\title{
Prevalence and Factors Associated with Dermatophytes in Equine: A Study of Hospital Demand
} \author{
Ana Karina Argumedo Jimenez ${ }^{1}$ and Maria Verônica de Souza ${ }^{1 *}$ \\ ${ }^{1}$ Department of Veterinary, Universidade Federal de Viçosa, Brazil \\ ${ }^{2}$ Department of Microbiology and Immunology Veterinary, Universidade Federal Rural do Rio de Janeiro, Brazil
}

Mariana Brettas Silva1 ${ }^{1}$, Lissandro Gonçalves Conceição ${ }^{1}$, Paula Dias Bevilacqua ${ }^{1}$, Sérgio Gaspar de Campos²,

Submission: June 19, 2018; Published: July 17, 2018

*Corresponding author: Maria Verônica de Souza, Department of Veterinary, Universidade Federal de Viçosa, Minas Gerais, Brazil, Email: msouzavet@gmail.com/msouza@ufv.br

\section{Mini Review}

The dermatophytosis is important in veterinary dermatology due to its zoonotic potential. Few studies were conducted worldwide to determine the prevalence of dermatophytosis in horses and they achieved distinct results. Within the equine species, the literature mentions the prevalence ranging between 2 and 44\% [1,2], in distinct locations. In Brazil, different geographic regions also presented different prevalence of dermatophytosis. In Paraiba state, the prevalence in rainy season was of 3.4\% [3]. The increased of human-domestic animal's interaction promotes the transmission of fungal diseases and increases the number of cases in human population. In this context, the investigation of zoonotic diseases is important to develop public prevention policies, since although the disease is not urgent or emergent, it results in financial losses. The aim of this study was to determine the prevalence of dermatophytes in equine from a Veterinary University Hospital during the period of one year in Minas Gerais state, Brazil.

The research protocol was approved by the Ethics Committee on Animal Use (No. 93/2014) and Ethics Committee on Research with Human Beings (No. 940.395). An epidemiological crosssectional prevalence study was performed. The animals were included in the research from May 2015 to April 2016. During this time, 224 horses were attended at the hospital. Only horses whose breeders or handlers accepted and agreed to participate by signing the authorization form were included in the study. To evaluate associated factors, the breeders/ handlers were submitted to a brief questionnaire about history of dermatopathies, food and sanitary management, presence of contacting horses or others contacting species, level of activity to which the animal was submitted and farm localization. The number of animals included was determined by statistical calculation by using the software OpenEpi 3.01, considering a total population of 200 horses, an expected frequency of $13 \%$ and a confidence limit of $5 \%$. The total population and the expected frequency were calculated according to the average number of animals attended in the last three years in the hospital and the average prevalence found in six different studies from distinct geographic regions. More than 121 animals were needed for confidence interval greater than 99\%. Thereby, 152 horses were included independent of the presence of dermatological lesions. In the present study, the majority (127/152) had information of injuries in other systems and, rarely skin problems. After physical evaluation, as routine veterinary care of equine, a detailed and specific dermatological examination was accomplished, followed by description of the macroscopic lesions, if there were any. Afterwards, samples of hair, scale and crusts were obtained by brushing the horse hair of different parts of the body, as well as skin scraping for parasitological examination, direct mycological examination and fungal culture. Prevalence, odds ratio (OR) and conditional maximumlikelihood estimate (CMLE) were the epidemiological analysis conducted. Descriptive and inferential statistics were used for the data analyses (Chi-square). The confidence interval for OR was determined by the exact method (mid-p exact). The software used for epidemiological and statistical evaluations were Epi Info 7.1.3 and OpenEpi version 3, 2006. The information obtained by questionnaire and physical and dermatological evaluations were analyzed regarding association with dermatophytosis. In order to facilitate statistical analysis according to age, animals were divided in two groups, one with animals less than 60 months old, and other with animals aged $\geq 60$ months. The results were interpreted considering significance level at $5 \%(\mathrm{P}<0.05)$.

So, 152 horses of different breeds and ages were studied. The prevalence of dermatophytes diagnosed by fungal culture 
was $19.08 \%(n=29)$. Of the positive animals, $28.3 \% \quad(n=14)$ did not present dermatological lesions. The most prevalent fungi species were T. equinum (41.4\%), M. gypseum (37.9\%), T. terrestre (17.2\%) and T. rubrum (3.5\%). The condition occurs in asymptomatic animals. In view of the high number of positive animals without dermatological lesions and its zoonotic character, further epidemiological studies are required in animals, as well as in humans being.

Culture of one $(3.5 \%)$ animal without cutaneous lesion revealed the growth of $\mathrm{T}$. rubrum. This etiological agent is anthropophilic, which is a frequent cause of dermatophytosis in the humans being as the etiological agent of tinea pedis and onychomycosis. It has also been described in dog [4] and sea lion [5], both with dermatological lesions. Because it is not adapted to the host, it would be expected that the only equine identified with T. rubrum presented dermatological lesions. However, the animal was asymptomatic. Thus, it is possible that the fungal agent was isolated due to environmental contamination. Breed, age, sex, sanitary and nutritional management, physical condition, season of the year, presence of contactants, practice of physical activity, as well as the presence and control of ectoparasites were not associated with fungus in horses. Some of biases associated with the study were the information related to the characteristics present in the questionnaire, and also the memory bias, since it demanded retroactive information from the breeders/handlers. In the conditions performed in the present study, using casuistry from a Veterinary Teaching Hospital, it can be concluded that the prevalence of dermatophytes in the region studied, from May 2015 to April 2016 is 19.1\%. Almost $50 \%$ of the animals may not present dermatological lesions, indicating that the equine, like cats, can act as an asymptomatic carrier. Most animals are positive for T. equinum and T. rubrum may be infectious for horses as well. The authors declare if any economic interest or any conflict of interest exist.

\section{References}

1. Nweze EI (2011) Dermatophytoses in domesticated animals. Rev Inst Med Trop São Paulo 53(2): 95-99.

2. Schaffer PA, Wobeser B, Dennis MM, Duncan CG (2013) Non-neoplasic lesions of equine skin in the central United States and Canada: A retrospectie study. Can Vet J 54(3): 262-266.

3. Pessoa AFA, Pessoa CRM, Neto EGM, Dantas AFM, Riet Correa F (2014) Doença de pele em equídeos no Seminário brasileiro. Pesq Vet Bras 34(8): 743-748.

4. Rooji PV, Declercq J, Beguin H (2012) Canine dermatophytosis caused by Trichophyton rubrum: An example of man-to-dog transmission. Mycosis 55(2): e15-e17.

5. Quintard B, Lohmann C, Lefaux B (2015) A case of Trychophyton rubrum dermatophytosis in a Patagonian Sea Lion (Otaria byronia). J Zoo Wildlife Med 46(3): 621-623.

\section{Your next submission with Juniper Publishers will reach you the below assets}

- Quality Editorial service

- Swift Peer Review

- Reprints availability

- E-prints Service

- Manuscript Podcast for convenient understanding

- Global attainment for your research

- Manuscript accessibility in different formats ( Pdf, E-pub, Full Text, Audio)

- Unceasing customer service

Track the below URL for one-step submission https://juniperpublishers.com/online-submission.php 